
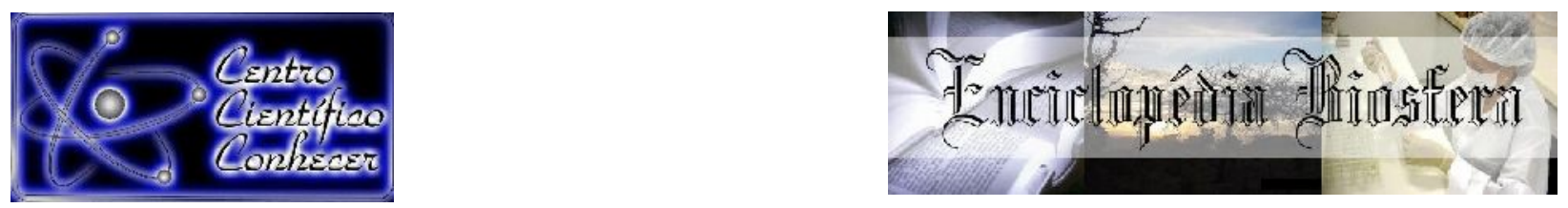

\title{
GESTÃO ESCOLAR DE ATIVIDADE INTERDISCIPLINAR: UM RELATO DE EXPERIÊNCIA NO IFTM
}

\author{
Paulo Henrique Santana de Oliveira'; Fábio Ricardo Mizuno Lemos ${ }^{2}$; Laila Lidiane \\ da Costa Galvão ${ }^{3}$; Lucas Fagundes Vaz ${ }^{4}$ \\ ${ }^{1}$ Mestre em Gestão Organizacional pelo Programa de Pós-Graduação em Gestão \\ Organizacional da Universidade Federal de Goiás, Catalão-GO, Brasil. \\ (paulhsdeoliveira@gmail.com) \\ ${ }^{2}$ Doutor em Educação pela Universidade Federal de São Carlos, \\ São Carlos-SP, Brasil. \\ ${ }^{3}$ Mestra em Gestão Organizacional pelo Programa de Pós-Graduação em Gestão \\ Organizacional da Universidade Federal de Goiás, Catalão-GO, Brasil. \\ ${ }^{4}$ Especialista em Gestão de Tecnologia da Informação pela Universidade Candido \\ Mendes, Rio de Janeiro-RJ, Brasil.
}

\section{Recebido em: 06/04/2018 - Aprovado em: 10/06/2018 - Publicado em: 20/06/2018 DOI: 10.18677/EnciBio_2018A132}

\begin{abstract}
RESUMO
A tecnologia ligada à informação/comunicação tem relevante papel no ambiente organizacional, pois tem potencial para facilitar a gestão de processos, inclusive, no ambiente acadêmico. Nesse sentido, o presente trabalho teve o objetivo de relatar uma experiência de gestão de processos em relação a uma atividade acadêmica desenvolvida no Instituto Federal do Triângulo Mineiro (IFTM) - Campus Patrocínio. Tal atividade consistiu na elaboração de uma avaliação para turmas do ensino médio contendo questões de múltipla escolha abrangendo todas as matérias do curso, de modo interdisciplinar (questões envolvendo os conhecimentos de dois ou mais componentes curriculares), semelhante ao que ocorre no Exame Nacional do Ensino Médio (ENEM). Para facilitar o processo de correção e gerenciamento, foi desenvolvido um software para corrigir eletronicamente as provas e fazer a exportação dos dados em formato de planilha eletrônica. Assim, com os dados organizados foi possível a elaboração de gráficos para análise estatística das provas/questões. Com a análise dos resultados foi possível construir um panorama para a tomada de decisões sobre as próximas avaliações, de forma a colaborar para a melhora contínua do instrumento de avaliação.
\end{abstract}

PALAVRAS-CHAVE: desenvolvimento de software; gestão de processos; relato de experiência.

\section{SCHOOL MANAGEMENT OF INTERDISCIPLINARY ACTIVITY: A REPORT OF EXPERIENCE IN THE IFTM}

\begin{abstract}
The technology associated with information and communication has a relevant role in the organizational environment, since it has the potential to facilitate the management of processes, including in the academic environment. The present paper had the objective of reporting a process management experience of an
\end{abstract}


academic activity developed at the Federal Institute of the Triângulo Mineiro (IFTM) Campus Patrocínio. The activity consisted in the elaboration of an evaluation for high school classes containing multiple choice questions covering all subjects of the course, in an interdisciplinary way (questions involving the knowledge of two or more curricular components); similar to what occurs in the National High School Exam (ENEM). To facilitate the process of correction and management, software was developed to correct the evidence and to export the data in spreadsheet format. With the data organized it was possible to elaborate graphs for statistical analysis of the questions. The analysis of the results allowed constructing a panorama for the decision making on the next evaluations and continuous improvement of the evaluation instrument.

KEYWORDS: software development; processes management; report of experience.

\title{
INTRODUÇÃO
}

A tecnologia ligada à informação/comunicação tem relevante papel no ambiente organizacional, pois tem potencial para facilitar a gestão de processos, inclusive, no ambiente acadêmico. Estão presentes em trabalhos científicos relatos em que a tecnologia é entendida como facilitadora acerca de gestão de processos e, portanto, alguns recortes pontuais serão elencados neste estudo para sua fundamentação e discussão.

Somado a isto, é importante ressaltar que a gestão de atividades escolares também merecem especial atenção, sobretudo no que diz respeito a inovações na educação. Neste sentido, Curi e Galvão (2017, p. 508) ressaltam que

\begin{abstract}
Apesar de a inovação ser antiga na história humana, só recentemente ela foi estudada, teorizada, e teve seus mecanismos e variações elencados e conhecidos. Isso, por óbvio, está diretamente relacionado com o momento histórico atual, início do século $\mathrm{XXI}$, e com os impactos da globalização, época em que a prática inovadora ganhou dimensões profissionalizadas. Em tempo de transformações constantes, inovar é palavra de ordem. A busca por uma mudança de postura, sobretudo na Educação, é uma demanda perene, e soluções diferentes devem ser incorporadas diante dos novos modelos de família, das novas profissões e até mesmo de uma nova interpretação da realidade. Trata-se também da necessidade de adequar o nível escolar, no caso o Integrado, às demandas típicas da faixa etária de seu público: adolescentes e jovens. Enfim, inovar é preciso; inclusive, na educação.
\end{abstract}

Segundo Capaverde e Vazquez (2015), no âmbito judiciário brasileiro a implantação de sistemas eletrônicos para tramitação de processos judiciais não atenderam exclusivamente demandas constitucionais, mas sim demandas sociais crescentes que exigem cada vez mais celeridade da justiça brasileira. Em seus estudos os autores adentraram no campo da aprendizagem organizacional, considerando mudanças operacionais advindas da implantação de sistemas eletrônicos utilizados para a tramitação de processos judiciais.

Reis et al. (2015) salientam o importante papel estratégico da tecnologia da informação e comunicação (TIC) na área da saúde, em relação ao ganho em termos de eficiência, planejamento e controle de atividades primordiais no âmbito hospitalar. Os autores destacam a versatilidade e demais ganhos que se tem com a utilização de TIC, apontando além dos sistemas de gestão, de informação e comunicação, os 
sistemas de prontuário eletrônico que, por sua vez, são ferramentas de apoio ao serviço médico que permitem aos gestores a coleta de uma ampla variedade de informações demográficas do paciente, dados clínicos e de medicação.

$\mathrm{Na}$ área da educação, em nível de governo federal há na legislação vigente Lei de Diretrizes e Bases da Educação Nacional (BRASIL, 1996) - artigos que oferecem estímulo para que a educação também alcance toda a sociedade por meio da modalidade de educação a distância (EAD). Subentendido nas entrelinhas está colocado que há necessidade de TICs para que esta modalidade de ensino e de aprendizagem aconteça. Portanto, de acordo com Moré et al. (2012):

$\mathrm{Na}$ aplicação das técnicas desenvolvidas para o ambiente EaD na sala de aula, diversas possibilidades se abrem - novos conteúdos são adaptados constantemente aos ambientes virtuais, ganha força o estudo não presencial, evidencia-se o dinamismo dos conteúdos multimídias, se expande a capacidade dos professores de acompanharem a frequência de estudo de seus alunos, enfim, uma nova e poderosa forma de conduzir o processo ensino-aprendizagem toma forma.

Neste contexto, evidencia-se a importância dos recursos tecnológicos nos diversos setores e ou segmentos da sociedade contemporânea (saúde, educação, segurança, economia, cultura etc.). Cada vez mais a sociedade está dependente da comunicação digital/virtual para executar atividades de rotina, de forma prática, segura e versátil e, dessa forma, a comunicação digital/virtual possibilita que as organizações sejam mais produtivas - eficientes e eficazes. Em consonância, Pereira e Silva (2012, p. 152), salientam a relevância dos recursos tecnológicos apontando que

As mudanças ocorridas nas últimas décadas, sobretudo os avanços tecnológicos, têm relevância nos setores público e privado, bem como nos contextos social, político e econômico. As modificações ocasionadas nos processos de desenvolvimento, e suas consequências na democracia e cidadania, convergem para uma sociedade caracterizada pela importância crescente dos recursos tecnológicos e pelo avanço das Tecnologias de Informação e Comunicação (TICs) com impacto nas relações sociais, empresariais e nas instituições.

No contexto acadêmico brasileiro há uma preocupação quanto a preparação dos alunos que cursam ensino nível médio para ingressarem em cursos superiores. Atualmente para se ter acesso a cursos superiores de universidades públicas brasileiras qualquer indivíduo deve se submeter ao Exame Nacional do Ensino Médio (ENEM) que segundo Ministério da Educação e Cultura (2018, p. s/p) "foi criado no ano de 1998" pelo Ministério da Educação (MEC) cujo objetivo é o de "avaliar o desempenho do estudante ao fim da escolaridade básica" e, através da nota obtida ele acessará o Sistema de Seleção Unificada (SISU ${ }^{1}$ ) para se inscrever e concorrer às vagas nos cursos ofertados pelas universidades. Sendo assim, as instituições de ensino médio conduzem e preparam os estudantes que têm interesse 1

O Sistema de Seleção Unificada (Sisu) é o sistema informatizado, gerenciado pelo Ministério da Educação (MEC), pelo qual instituições públicas de educação superior oferecem vagas a candidatos participantes do Exame Nacional do Ensino Médio (Enem) (SISU, 2018). 
em ingressar em algum curso superior para a realização do ENEM. Confirma-se o modelo de seleção para o ingresso em cursos de universidades públicas/privadas conforme colocação de Santos (2011, p. 198-199).

Então, somado a outros fins, o ENEM passou a ser também critério de avaliação para a entrada em muitas universidades do país. O número de inscritos sobe proporcionalmente ao número de universidades, preferencialmente públicas, que aderem ao processo, como anteviu o ministério. Algumas universidades, como a Federal do Ceará, tornam o ENEM obrigatório para todos os que desejam fazer seu vestibular.

Jucá (2006, p. 26) corrobora com a temática deste relato de experiência apontando que:

[...] o conhecimento dos princípios básicos de informática torna-se indispensável à formação da cidadania contemporânea. Por isso, é necessário que o ensino possa fornecer um conjunto de competências específicas que permitam perceber e interagir com a evolução tecnológica presente no cotidiano.

A interdisciplinaridade nas provas do ENEM é o resultado da junção de diversas disciplinas e temas colocados de forma a estimular a maneira do pensar diante das mais distintas situações e vivências, de forma que os alunos saibam interpretar e visualizar situações-problema de modo mais assertivo. Segundo o INEP (2005, p. 8):

O Enem tem, ainda, papel fundamental na implementação da Reforma do Ensino Médio, ao apresentar, nos itens da prova, os conceitos de situação-problema, interdisciplinaridade e contextualização, que são, ainda, mal compreendidos e pouco habituais na comunidade escolar. A prova do Enem, ao entrar na escola, possibilita a discussão entre professores e alunos dessa nova concepção de ensino preconizada pela LDB, pelos Parâmetros Curriculares Nacionais e pela Reforma do Ensino Médio, norteadores da concepção do exame.

O termo interdisciplinaridade ainda é algo de difícil compreensão para muitos. No entanto, busca-se à luz de estudos de pesquisadores o discernimento necessário a fim de compreender com mais clareza o significado e sentido do termo em questão, pois é de extrema importância no meio educacional. Para Mozena e Ostermann (2017, p. 96), a interdisciplinaridade:

[...] tem sido vinculada como um dos aspectos fundamentais de uma educação de qualidade. Esse fato é confirmado pelo vertiginoso aumento nos últimos anos do estudo do tema em várias áreas de pesquisa em ensino ou educação, além da consagração na legislação brasileira da interdisciplinaridade como base de organização e sua institucionalização no currículo, já que $20 \%$ da carga horária anual da escola básica brasileira deve ser destinada a projetos interdisciplinares. 
Fazenda (2008, p. 12) aponta que "[...] a exigência interdisciplinar que a educação indica reveste-se, sobretudo de aspectos pluri disciplinares e transdisciplinares que permitirão novas formas de cooperação, principalmente o caminho no sentido de uma policompetência". Fazenda (2008, p. 13) ainda diz que:

A constatação inicialmente evidenciada, resultado de anos de pesquisa na temática da interdisciplinaridade, refere-se ao caráter intuitivo das práticas comumente chamadas interdisciplinares. Nelas impera a circulação de conceitos e esquemas cognitivos sem consistência, ou apenas disciplinarmente consistentes, portanto, insuficientes para agir ou pensar interdisciplinarmente. Essa constatação tem-nos compelido a um trabalho de construção conceitual interdisciplinar que visa ao ingresso de olhares paralelos e à abertura a esses olhares, convergentes ou divergentes, em suma, ao exercício pleno da ambiguidade nas questões de educação.

Considerando-se que os conteúdos das provas do ENEM são elaborados de forma interdisciplinar, ou seja, de forma que envolvam conhecimentos de dois ou mais componentes curriculares, a equipe de profissionais da educação do Instituto Federal do Triângulo Mineiro (IFTM) Campus Patrocínio elaborou um projeto multidisciplinar para a elaboração de uma prova que ocorre a cada trimestre, com o intuito de propiciar aos alunos experiências similares ao ENEM.

Tendo como base o contexto organizacional de instituições de ensino públicas, as TICs e o conceito de interdisciplinaridade, este estudo teve o objetivo de relatar uma experiência de gestão de processos em relação a uma atividade acadêmica desenvolvida no IFTM Campus Patrocínio. Tal atividade acadêmica consistiu na elaboração de uma avaliação para turmas do ensino médio contendo questões de múltipla escolha abrangendo todas as matérias do curso, de modo interdisciplinar (questões envolvendo os conhecimentos de dois ou mais componentes curriculares), semelhante ao que ocorre no ENEM.

\section{MATERIAL E MÉTODOS}

O trabalho se caracteriza como um relato de experiência analítico descritivo. Ressalta-se que os autores deste trabalho estiveram envolvidos direta ou indiretamente na experiência relatada no ano de 2014.

A estrutura organizacional do IFTM é constituída por profissionais docentes e técnicos administrativos em educação (TAE). A equipe propositora e executora da atividade, objeto deste estudo, contou com técnicos especializados na área pedagógica, técnicos em assistência ao aluno, técnicos em tecnologia da informação e professores do núcleo comum e núcleo técnico, uma vez que a modalidade de ensino nesta instituição é ensino médio integrado ao ensino técnico.

O propósito da experiência relatada foi o de aprimorar e inovar as atividades acadêmicas comumente aplicadas no ensino médio com o intuito de preparar melhor os alunos de ensino médio.

A partir da definição do escopo da avaliação verificou-se a necessidade de obtenção de dados detalhados na forma eletrônica, bem como avaliar os resultados desta experiência a partir da estatística descritiva extraída da correção das provas. Mediante demanda identificada, foi proposto e desenvolvido um sistema eletrônico de forma que neste, a equipe envolvida no projeto (atividade pedagógica) lançasse as respostas das questões marcadas/assinaladas pelos alunos nas provas realizadas em papel. 
Ao final do lançamento das respostas o sistema eletrônico apresentou dados estatísticos organizados em forma de listas ordenadas por percentuais, tabelas e gráficos. Dessa forma, foi possível reunir a equipe e discutir formas de aprimoramento das questões interdisciplinares colocadas na avaliação.

O sistema eletrônico foi desenvolvido para funcionar em ambiente web (online). A linguagem de programação escolhida foi a Hypertext Preprocessor, originalmente Personal Home Page (PHP) e o banco de dados empregado foi o $M y S Q L$, por se tratar de tecnologias gratuitas e utilizadas em larga escala na área de desenvolvimento de sistemas, além de subsidiar vasta documentação e referencial para desenvolvedores de sistemas. Não existia sistema eletrônico com esta finalidade no IFTM Campus Patrocínio.

Sistemas eletrônicos podem ser entendidos conforme o fluxograma abaixo (figura 1), que apresenta a entrada dos dados gerada através da inserção destes pelo utilizador, o processamento, que é realizado pelo equipamento através de cálculos matemáticos e a saída dos dados de forma organizada e útil para a visualização do usuário:

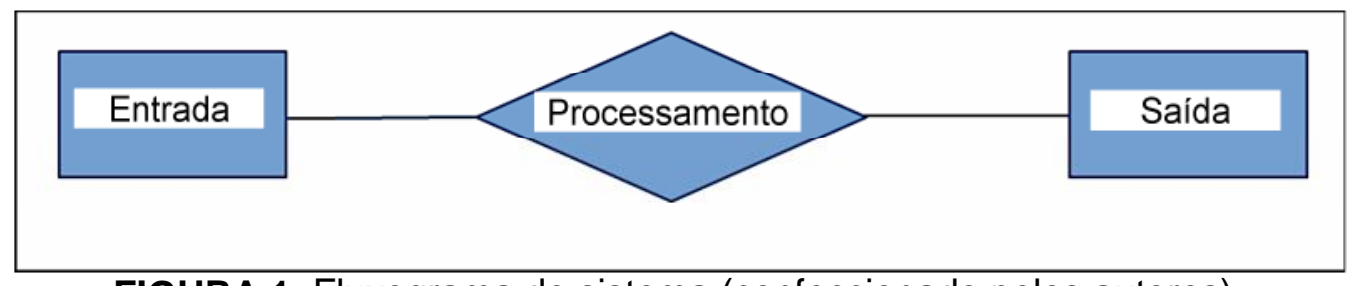

FIGURA 1. Fluxograma de sistema (confeccionado pelos autores).

As avaliações foram produzidas com o objetivo de estarem muito parecidas com a prova do ENEM, sob o ponto de vista de diagramação e do perfil das questões. Cada detalhe foi pensado para que o aluno cursista se acostumasse com o estilo de provas tanto na questão estilística quanto no quesito tempo gasto para a realização.

\section{RESULTADOS E DISCUSSÃO}

Um ponto que merece destaque ao longo desta experiência foi o de que houve inovação no processo de gestão escolar na referida instituição, dado contexto de não haver sistema informatizado que atendesse esta demanda. Por unanimidade a equipe executora do projeto debateu e salientou a satisfação em relação à eficiência do sistema, pois sua utilização trouxe praticidade e ganho de tempo para análises das respostas dos estudantes, ponto chave da proposta do sistema implementado. Ressalta-se que, como o objetivo da avaliação foi um pré-treino para os pretensos candidatos ao ENEM, a avaliação era composta de questões objetivas e redação na forma de dissertação argumentativa. A redação foi corrigida no modo convencional, pois há quesitos subjetivos que só podem ser avaliados se a correção for realizada por docentes da área.

A experiência vivenciada no IFTM vai ao encontro dos estudos realizados por Moré et al. (2012), Capaverde e Vazquez (2015) e Reis et al. (2015), no que diz respeito aos benefícios provenientes do uso das TICs em situações diversas, devido aos ganhos na gestão de processos. Evidencia-se, conforme citado anteriormente, a

2

O MYSQL é o banco de dados de código aberto mais conhecido no mundo. Com comprovado desempenho, confiabilidade e facilidade de uso, o MySQL tornou-se a principal opção de banco de dados para aplicativos baseados na Web, usado por propriedades da Web de alto perfil, incluindo Facebook, Twitter, YouTube e todos os cinco sites principais (ORACLE, 2017). 
importância dos recursos tecnológicos nos diversos setores e ou segmentos da sociedade contemporânea (saúde, educação, segurança, economia, cultura etc.), e neste caso específico, em uma instituição de ensino pública que busca qualidade, inovação e ampliação na oferta de seus serviços para a sociedade.

No ano em que houve a utilização do sistema eletrônico havia três cursos na modalidade ensino médio integrado ao ensino técnico, sendo eles: Administração, Eletrônica e Montagem e Manutenção de Computadores. Com base na figura 2, percebe-se que os dados foram agrupados e classificados de forma a exibir o nome completo do aluno e o curso/turma que ele está inserido, além da sua nota de redação e nota da prova objetiva, estas que somadas permitem calcular e também exibir a nota final.

\begin{tabular}{|c|c|c|c|c|c|}
\hline Nome Completo & Turma & Estatística & $\begin{array}{c}\text { Nota Prova } \\
\text { Objetiva }\end{array}$ & $\begin{array}{c}\text { Nota } \\
\text { Redaçăo }\end{array}$ & $\begin{array}{l}\text { Nota } \\
\text { Final }\end{array}$ \\
\hline 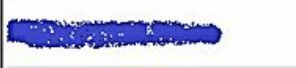 & Manutenção & $\frac{\text { Acertos e Erros por }}{\underline{\text { Arrea }}}$ & 36 & 5.00 & 9.50 \\
\hline 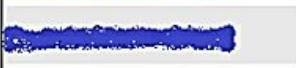 & Administração & $\frac{\text { Acertos e Erros por }}{\text { Área }}$ & 28 & 2.80 & 6.30 \\
\hline 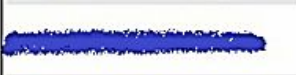 & Eletrônica & $\frac{\text { Acertos e Erros por }}{\text { Área }}$ & 30 & 2.50 & 6.25 \\
\hline 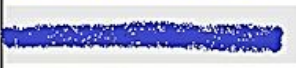 & Eletrônica & $\frac{\text { Acertos e Erros por }}{\text { Área }}$ & 40 & 2.70 & 7.70 \\
\hline 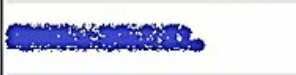 & Manutenção & $\frac{\text { Acertos e Erros por }}{\underline{\text { Área }}}$ & 17 & 5.00 & 71.25 \\
\hline 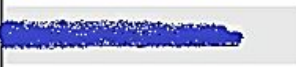 & Administração & $\frac{\text { Acertos e Erros por }}{\text { Área }}$ & 33 & 4.50 & 7.80 \\
\hline 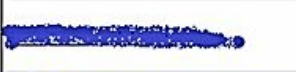 & Eletrônica & $\frac{\text { Acertos e Erros por }}{\underline{\text { Area }}}$ & 27 & 4.00 & 73.75 \\
\hline 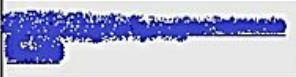 & Administração & $\frac{\text { Acertos e Erros por }}{\underline{\text { Area }}}$ & 39 & 3.90 & 87.75 \\
\hline
\end{tabular}

FIGURA 2. Exibição de notas por turma (obtida pelos autores).

No topo da figura 1 têm-se alinhados os links para os relatórios por cursos (Relatório de Questões ADM, Relatório de Questões ELE e Relatório de Questões MAN) de modo que cada questão da prova seja listada e exibido os percentuais de alunos que assinalaram as respectivas alternativas (A, B, C ou D). Há também no sistema o acesso às notas individuais de cada aluno incluindo a opção de atualização da nota de redação. Dessa forma, a nota final já é calculada tendo em vista a média das notas da prova objetiva e da redação, conforme figura 3.

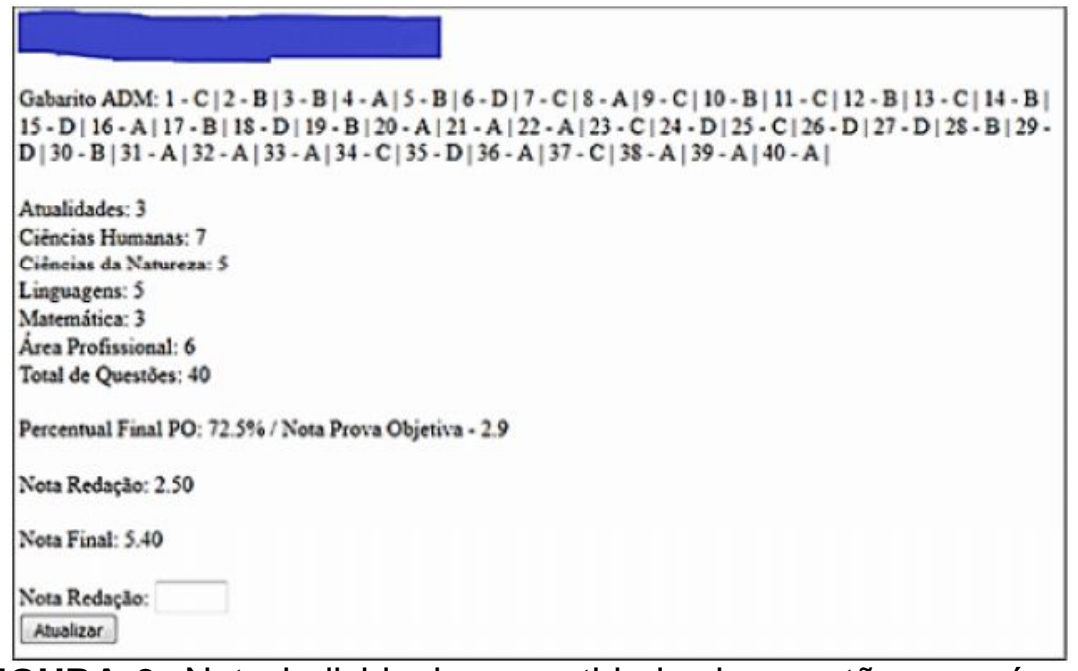

FIGURA 3. Nota individual e quantidade de questões por área (obtida pelos autores). 
$\mathrm{Na}$ figura 4 esta exibido o relatório por questões, pois este é o principal propósito do sistema eletrônico. A exibição do percentual de alunos que acertaram determinadas questões e suas respectivas áreas mostra à equipe pedagógica onde é preciso melhorar na elaboração de questões.

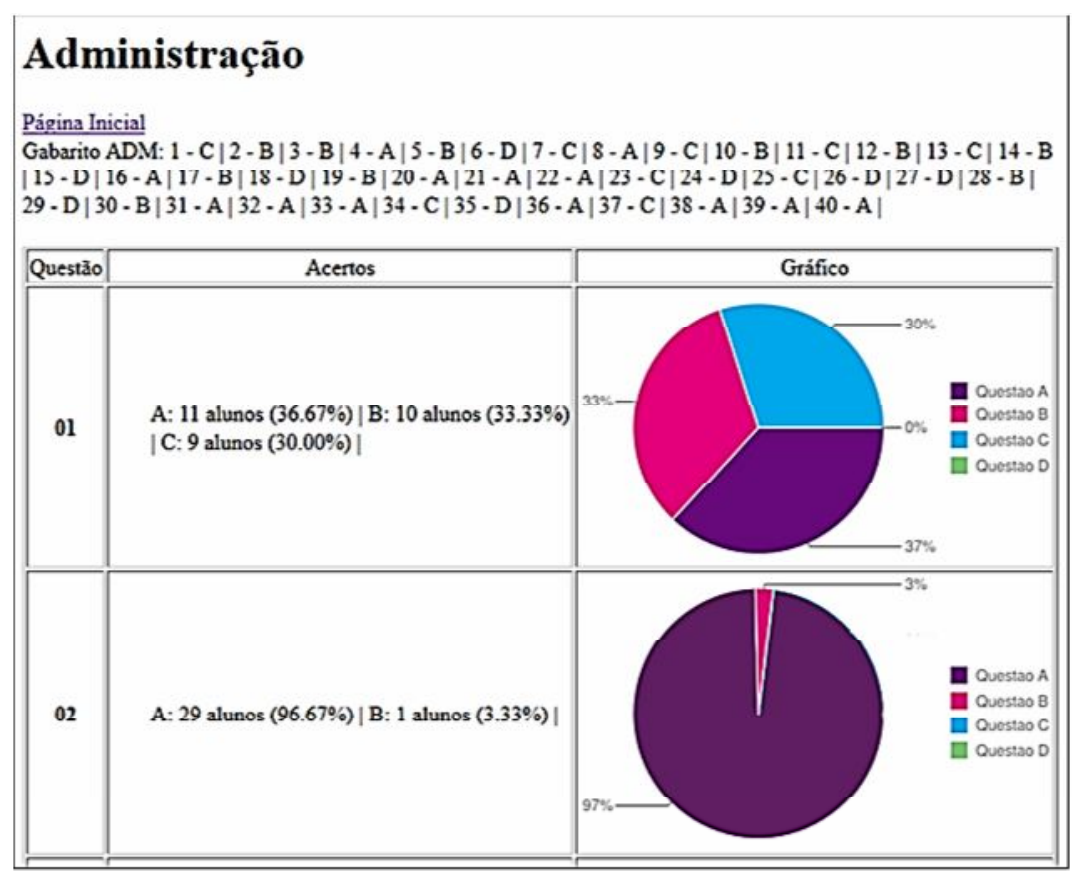

FIGURA 4. Percentual de acertos por questões (obtida pelos autores).

De acordo com a figura 4 já seria possível à equipe pedagógica identificar alguma falha na elaboração da questão, uma vez que segundo o gabarito a alternativa correta referente à questão 02 era a alternativa $B$ e $96,67 \%$ dos alunos responderam a alternativa $A$.

A figura 5 mostra que é possível identificar que a questão 03 pode ter alcançado o objetivo, uma vez que $63,33 \%$ dos alunos assinalaram a alternativa correta (opção B - conforme gabarito exibido na figura 4). Dessa forma, pode-se dizer que a referida questão pode ter sido bem elaborada e segundo as normas da prova do ENEM seria uma questão similar e com nota mais alta, pois a julgar pelo percentual de acertos é uma questão bem elaborada e ao mesmo tempo uma questão em que a maioria dos alunos assinalou a alternativa correta.

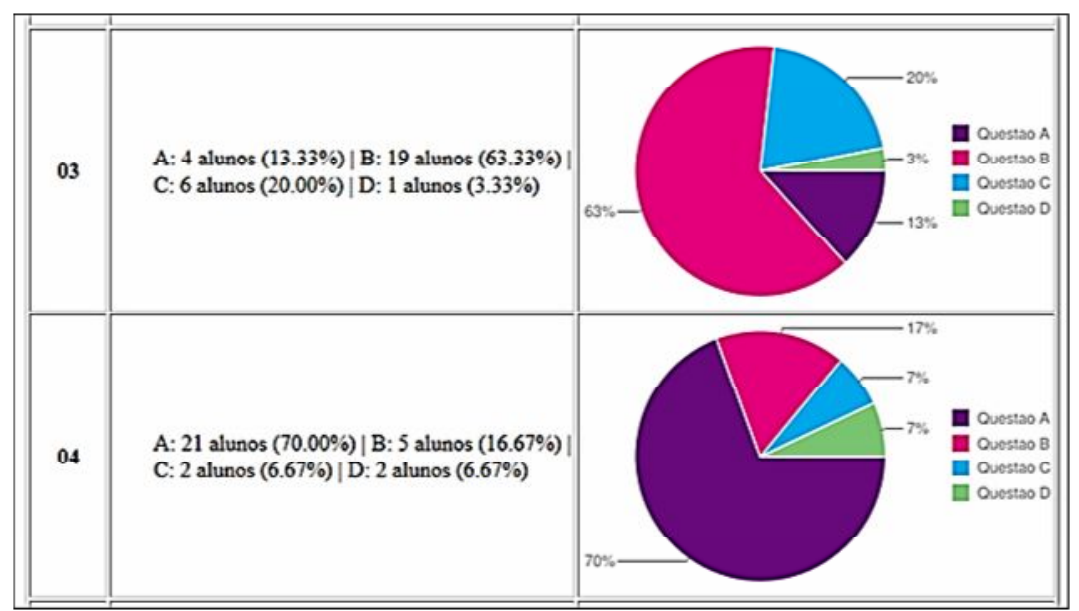

FIGURA 5. Percentual de acertos por questão (obtida pelos autores). 
Ao final da primeira avaliação foi possível identificar as dificuldades dessa atividade de gestão acadêmica. O principal ponto foi a dificuldade na elaboração de questões interdisciplinares, pois mesmo passando pelo crivo de profissionais da área de português/letras, as questões ora elaboradas podem não ter atingido o objetivo de averiguar o conhecimento aprendido em sala de aula. Entretanto, é preciso que se criem atividades inovadoras no ensino, promovendo cada vez mais experimentações e avaliações do que foi criado. Outro importante dado estatístico foi o percentual de acertos agrupados por área e depois por questões, conforme quadro 1.

TABELA 1. Percentual de acertos agrupados por área.

\begin{tabular}{ccc}
\hline Área & Questão & Acertos (\%) \\
\hline Atualidades & Questão 01 & $33.33 \%$ \\
Atualidades & Questão 02 & $96.67 \%$ \\
Atualidades & Questão 03 & $63.33 \%$ \\
Atualidades & Questão 04 & $70.00 \%$ \\
Atualidades & Questão 05 & $76.67 \%$ \\
\hline
\end{tabular}

Elaborada pelos autores.

Na forma como estão expostos os dados percentuais de acertos na tabela 1 foi possível visualizar de forma geral que na área de atualidades a turma de administração teve alto índice de acertos. Isto permitiu à equipe pedagógica uma análise mais aprofundada tendo como base 0 enunciado das questões, as alternativas relacionadas e o número de acertos. Assim, é possível mensurar se o grau de dificuldade está condizente com o que é exigido nas provas do ENEM.

Assim como na tabela 1, na tabela 2 verifica-se que há algo de errado com umas das questões cujo percentual de acertos foi de $100 \%$. Em relação às outras questões elaboradas da área de Ciências da Natureza parece ter atingido o objetivo da prova, pois nem todos os alunos acertaram as questões e nem todos os alunos erraram as questões.

TABELA 2. Percentual de acertos por área.

\begin{tabular}{ccc}
\hline Área & Questão & Acertos (\%) \\
\hline Ciências da Natureza & Questão 13 & $86.67 \%$ \\
Ciências da Natureza & Questão 14 & $100.00 \%$ \\
Ciências da Natureza & Questão 15 & $73.33 \%$ \\
Ciências da Natureza & Questão 16 & $26.67 \%$ \\
Ciências da Natureza & Questão 17 & $26.67 \%$ \\
Ciências da Natureza & Questão 18 & $83.33 \%$ \\
Ciências da Natureza & Questão 19 & $70.00 \%$ \\
\hline
\end{tabular}

Elaborada pelos autores.

Nas provas subsequentes foi possível explorar mais a dinâmica de avaliações interdisciplinares e corrigir os pontos falhos ou pontos em que os docentes tiveram mais dificuldades na elaboração de questões. Outro ponto identificado e discutido pela equipe pedagógica foi que avaliações inovadoras com questões interdisciplinares fazem com que os alunos exercitem sua habilidade cognitiva e melhorem sua visão sobre e entre as disciplinas ou componentes curriculares. Além disso, o prazo determinado para que os alunos realizem as avaliações é similar ao prazo que é disponibilizado na avaliação do ENEM.

Sobre a parte operacional das atividades de gestão acadêmica, sabe-se que há diferentes softwares que fazem gestão de processos dessas tarefas ENCICLOPÉDIA BIOSFERA, Centro Científico Conhecer - Goiânia, v.15 n.27; p. 15532018 
administrativas e pedagógicas - no ambiente organizacional escolar. Porém, ressalta-se que é possível haver dificuldades quanto à sua utilização. As desvantagens podem estar relacionadas à dificuldade de manuseio dos softwares. Todavia, as vantagens superam as desvantagens que, por sua vez, podem ser eliminadas com treino e prática diária utilizando os softwares. A este respeito, Cavalcante et al., (2016, p. 165) corroboram com este raciocínio e apontam que as instituições de ensino "passaram a adotar as tecnologias de informação para maior agilidade em suas atividades administrativas e pedagógicas". Além disso, "muitos softwares passaram a ser utilizados no processo de gerenciamento escolar". Os autores destacam que é fundamental a utilização de softwares nas instituições de ensino, pois proporcionam vantagens diversas e maior agilidade nas atividades pedagógicas.

Para elucidar de forma mais objetiva, Cavalcante et al., (2016, p. 163) apontam as principais difiçldades em trabalharem com softwares na modalidade escritório - pacote office, libreOffice ou similar. São elas: 1) demora do preenchimento das informações; 2) manuseio das planilhas e tabelas; 3) perda de informações. Por outro lado as vantagens são: 1) agilidade durante o preenchimento das informações; 2) segurança dos dados que são manipulados; 3) A facilidade no manuseio dos dados; 4) menor esforço e tempo; 5) facilidade na geração de relatórios; 6) a informatização dos dados. Neste contexto, em relação à desvantagem "perda de informações" se deve ao fato de que os arquivos podem ser infectados por vírus na rotina de tarefas administrativas, causando a perda dos arquivos.

Ainda sobre a utilização de softwares na área da educação, Bernardi (2010, p. 2-3) aponta a relevância e potencialidades ao utilizar softwares na educação para atender diversas demandas:

[...] é fundamental reconhecer as potencialidades das tecnologias disponíveis e a realidade em que a escola se encontra inserida. Esse reconhecimento favorece a incorporação de diferentes tecnologias (computador, Internet, TV, vídeo...) existentes na escola, à prática pedagógica e a outras atividades escolares nas situações em que possam trazer contribuições significativas. As tecnologias, entretanto, devem ser utilizadas de acordo com os propósitos educacionais da escola, fazendo uso de estratégias adequadas para propiciar ao aluno a aprendizagem, não podendo ser regida como a informatização do ensino, que reduz as tecnologias a meros instrumentos para instruir o aluno. No processo de incorporação das tecnologias na escola, aprende-se a lidar com a diversidade, a abrangência e a rapidez de acesso às informações, bem como com novas possibilidades de comunicação e interação, o que propicia novas formas de aprender, ensinar e produzir conhecimento.

3 O Microsoft Office é uma suíte de aplicativos para escritório que contém vários programas já conhecidos de outras versões desta suíte. Os mais comuns são o processador de textos (Word), de planilhas eletrônicas (Excel), de apresentações (PowerPoint), de bancos de dados (Access), e o cliente de e-mails (Outlook) (CARLOS, 2013 p. s/p).

$4 \quad$ LibreOffice é um pacote de produtividade de escritórios totalmente funcional e disponível gratuitamente. Seu formato de arquivo nativo é o OpenDocument, um padrão de formato aberto que está sendo adotado, por governos do mundo inteiro, como um formato necessário para a publicação e aceitação de documentos. O LibreOffice também pode abrir e salvar documentos em muitos outros formatos, incluindo aqueles utilizados por softwares proprietários (CARLOS, 2013 p. s/p). 
Neste contexto, vale frisar que a utilização de softwares não se restringe ao suporte administrativo e pedagógico, mas também está no cotidiano dos alunos. Ao perceber esta realidade será possível aprimorar o software analisado com vistas a proporcionar ao aluno responder automaticamente as questões sobre conteúdos abordados em sala de aula. Somado a isso a produção de texto em qualquer modalidade. Desdobrando um pouco mais esse processo, pode-se pensar em formas diversas de avaliação como, por exemplo, a implementação do sistema de avaliação TRI e avaliação as cegas dos textos produzidos, tudo isto de forma informatizada.

Outro ponto que merece destaque foi que a equipe pedagógica da escola em questão teve a iniciativa de se propor a inovar na gestão de processos, o que coaduna com a opinião de Fernandes et al., (2016, p. 896) quando afirmam que:

[...] a gestão escolar tem que perceber o uso das TIC como sendo um transformador do ambiente de aprendizagem, em sala de aula. Sair da postura apenas das aulas expositivas e se insurgir nas TIC, que vai além do uso televisão, microsystem ou mesmo um projetor multimídia, mas também utilizar a internet como ferramenta pedagógica, para tentar transformar as práticas de ensino/aprendizagem, e ter como foco o aluno como protagonista desse processo.

Destarte, o presente relato de experiência analítico atendeu ao objetivo proposto que foi o de divulgar uma experiência empírica com resultados satisfatórios e positivos para a instituição de ensino, bem como para os profissionais envolvidos no processo. Esta iniciativa é um diferencial da instituição de ensino em questão, pois trata-se de uma inovação e, portanto, o projeto foi ao encontro do pensamento de Curi e Galvão (2017, p. 508) em seu estudo, onde asseveram que "inovar é preciso; inclusive, na educação".

\section{CONCLUSÃO}

Retomando o objetivo deste estudo que foi o de relatar uma experiência de gestão de processos em relação a uma atividade acadêmica desenvolvida no IFTM Campus Patrocínio, por todo o exposto, a experiência realizada no IFTM em 2014 se mostrou importante para o processo formativo dos alunos. Temas e questões interdisciplinares fizeram com que os alunos tivessem contato com formas diversificadas de aprendizado que não fossem o método convencional.

Em relação a gestão escolar, verificou-se que a eficiência e eficácia na gestão de processos, quando as TICs são utilizadas como ferramenta base, apoio ou estratégica, foram potencializadas. Evidenciou-se que o sistema eletrônico desenvolvido e utilizado para esta atividade escolar trouxe maior ganho para análise estatística e para que se pudesse tomar importantes decisões e realizar melhorias no processo de ensino e de aprendizagem com a aplicação das avaliações periódicas.

Ao concluir a primeira experiência com o trabalho, foi possível à equipe entender as partes em que o sistema precisava ser melhorado nas próximas versões e como poderá gerar maiores benefícios acadêmicos para as partes envolvidas. Dentre esses pontos importantes levantados, elenca-se o modelo de correção 
baseado na Teoria de Resposta ao Item (TRI), utilizado no ENEM. Ao ser implementado nas novas versões do sistema das provas do IFTM Campus Patrocínio e possivelmente em outros campi dos Institutos Federais e ou quaisquer outras instituições de ensino que aderirem a ideia, este treinamento - aplicação de provas e correção eletrônica -, possibilitará ao estudante e aos demais envolvidos uma visualização e aproximação do que acontece na prova do ENEM. O que gerará para o estudante uma resposta mais próxima à realidade, fazendo com que ele perceba o que precisa ser aprimorado em seus estudos.

\section{REFERÊNCIAS}

BERNARDI, S.T.; Utilização de softwares educacionais nos processos de alfabetização, de ensino e aprendizagem com uma visão psicopedagógica. Revista de Educação do Ideau, v. 5, n. 10, p. 1-15, jan/jun. 2010. Disponível em: <https://www.ideau.com.br/getulio/restrito/upload/revistasartigos/210_1.pdf>.

BRASIL. Lei 9.394, de 20 de dezembro de 1996. Estabelece as diretrizes e bases da educação Nacional. Brasília: Casa Civil, 1996. Disponível em: <http://www.planalto.gov.br/ccivil_03/Leis/L9394.htm>. Acesso em: 06 jun. 2018.

CAPAVERDE, C. B.; VAZQUEZ, A. C. S. Implantação de processo eletrônico no sistema judiciário: um estudo sobre aprendizagem organizacional em uma secretaria de gestão de pessoas. Revista Eletrônica de Administração, v. 21, n. 2, p. 462490, ago. 2015. Disponível em: <http://dx.doi.org/10.1590/14132311.0592014.53649>. Doi: 10.1590/1413-2311.0592014.53649.

CARLOS, E. S. Conceitos básicos e modos de utilização de aplicativos para edição de textos, planilhas e apresentações: ambiente Microsoft Office 2013 e LibreOffice versão 4.1 ou superiores. Disponível em: <http://centraldefavoritos.com.br/2016/11/04/conceitos-basicos-e-modos-deutilizacao-de-aplicativos-para-edicao-de-textos-planilhas-e-apresentacoes-ambientemicrosoft-office-2013-e-libreoffice-versao-4-1-ou-superiores/>. Acesso em: 06 jun. 2018.

CAVALCANTE, K. S.; OLIVEIRA, L. R. P.; OLIVEIRA, I. S. M. Análise de Softwares de Gestão Escolar Open Source para uma Escola Privada do Ensino Básico. Nuevas Ideas en Informática Educativa, v. 12, p. 157-166, 2016. Disponível em: <http://www.tise.cl/volumen12/TISE2016/157-166.pdf>.

CURI, L. M.; GALVÃO, L. L. C. Atividades Integradoras: inovação no Integrado. In: ARAÚJO, A. C.; SILVA, C. N. N. (Org.). Ensino Médio Integrado no Brasil: fundamentos, práticas e desafios. Brasília: IFB, p. 508-524.2017.

FAZENDA, I. C. A. Didática e interdisciplinaridade. 13. ed. Campinas: Papirus, 2008.

5

A nota do Enem é calculada mediante um modelo matemático da Teoria da Resposta ao Item (TRI), em que cada questão é um item. Essa teoria considera para o cálculo da nota a consistência da resposta segundo o grau de dificuldade de cada questão. 
FERNANDES, G. P.; GONÇALVES, P.; AMORIM, A. Gestão de recursos tecnológicos em colégios estaduais baianos: as múltiplas possibilidades de ação pedagógica na EJA. Ensaio: Avaliação e Políticas Públicas em Educação, v.24, n. 93, p. 890-909, out./dez. 2016. Disponível em: <http://www.scielo.br/pdf/ensaio/v24n93/1809-4465-ensaio-24-93-0890.pdf>. Doi: 10.1590/S0104-40362016000400006.

INEP. Instituto Nacional de Estudos e Pesquisas Educacionais Anísio Teixeira. Exame Nacional do Ensino Médio (Enem): fundamentação teórico-metodológica. Brasília: INEP, 2005.

INEP/Ministério da educação. Saiba o que é o Enem e prepare-se para as provas. Acessado em: 06 de junho de 2018. Disponível em: <http://www.ebc.com.br/educacao/2012/08/conheca-o-enem>.

JUCÁ, S. C. S. A relevância dos softwares educativos na educação profissional. Ciências \& Cognição, v. 8, p. 22-28, 2006. Disponível em: <http://cienciasecognicao.org/pdf/v08/cec_vol_8_m32689.pdf>.

MORÉ, R. P. O.; VIEIRA, G. T.; ARAÚJO, M. S.; COSTA, A. M. Formação docente e educação a distância: um estudo do cenário educativo de Santa Catarina. Revista de Ciências da Administração, v. 14, n. 32, p. 9-20, abr. 2012. Disponível em: <http://dx.doi.org/10.5007/2175-8077.2012v14n32p9>. Doi: 10.5007/21758077.2012v14n32p9.

MOZENA, E. R.; OSTERMANN, F. Dialogando sobre a interdisciplinaridade em ivani catarina arantes fazenda e alguns dos integrantes do grupo de estudos e pesquisa em interdisciplinaridade da Puc-Sp (Gepi). Revista Interdisciplinaridade, n. 10, p. 95-107, abr/2017. Disponível em: <https://revistas.pucsp.br/index.php/interdisciplinaridade/issue/download/1775/49>.

ORACLE. $O$ banco de dados de código aberto mais conhecido no mundo. Disponível em: <https://www.oracle.com/br/mysql/index.html>. Acesso em: 27 nov. 2017.

PEREIRA, D. M.; SILVA, G. S. As Tecnologias de Informação e Comunicação (TICs) como aliadas para o desenvolvimento. Cadernos de Ciências Sociais Aplicadas, n. 10, p. 151-174, agosto de 2012. Disponível em: <http://periodicos.uesb.br/index.php/cadernosdeciencias/article/viewFile/884/891>.

REIS, C.; MATTOS, M. M.; LENZI, F. C.; SANTOS, T. Tecnologias de informação em saúde: desafios e perspectivas a partir da avaliação dos usuários da rede pública de Blumenau (SC). Revista de Gestão Em Sistemas de Saúde, v. 4, n.1, p. 71-82, jan./jun. 2015. Disponível em: <http://dx.doi.org/10.5585/rgss.v4i1.115>. Doi: 10.5585/rgss.v4i1.115. 
SANTOS, J. M. C. T. Exame Nacional do Ensino Médio: entre a regulação da qualidade do Ensino Médio e o vestibular. Educar em Revista, Curitiba, Brasil, n. 40, p. 195-205, abr.jun. 2011. Editora UFPR. Disponível em: <http://www.scielo.br/pdf/er/n40/a13.pdf>. Doi: 10.1590/S0104-40602011000200013. 